\title{
Abstract: The societal impact and economic implications of the Last Arrow Ceremony
}

Tuhin Chakraborty and Bethany Hughes, $\mathrm{PhD}^{*}$

Department of American Culture, University of Michigan, Ann Arbor, MI 48109

During much of the 19th and early 20th centuries, federal Indian laws in the United States were primarily focused on addressing the "Indian problem." The 1887 General Allotment Act attempted to solve the problem by transferring tribally owned land to individual ownership by Native American families. The Last Arrow Ceremony was a ritual recognizing U.S. citizenship for Indians who accepted this allotted land. During the ceremony's existence from 1916 to 1918, it consisted of a federal Indian agent leading a Native American through a series of vignettes that demonstrated the transformation from Indian to white American. For men, these vignettes began by shooting an arrow, the "last arrow" that they would ever shoot. Women usually received a purse and a workbag to signify their entrance into Western-style domestic life. Along with Dr. Bethany Hughes of the Department of American Culture, I am working to conduct a study of the ceremony's creation, implementation, and impact on the social and economic status of the new Native
American landowners. Our research methodology consists of information from primary sources (e.g. newspaper coverage, photographs, papers of federal officials) and secondary sources (e.g. scholarly literature on federal Indian law and the allotment era). We seek to reconstruct the Last Arrow Ceremony to demonstrate that it was a product of assimilation-era policies, including not only allotment, but Christianization (Native people were given Christian names during this ceremony), that pushed transformation and the eventual extinction of Native Americans as a tribal civilization. Uncovering the Last Arrow Ceremony's genesis, execution, and outcomes will shed light on the larger issue of how the U.S. government has actively tried to erase Native Americans as a people, but has repeatedly failed because of the embodied and performative nature of federal Indian law.

^To whom correspondence should be addressed: drbh@umich.edu 